| GOSOS | Gaziosmanpaşa Üniversitesi Sosyal Bilimler Araştırmaları Dergisi Gaziosmanpasa University Social Sciences Researches Journal

(Kış 2016) 11/2: 125-138 / (Winter 2016) 11/2: 125-138

Makale Geliş Tarihi:24.08.2016. Yayın Kabul Tarihi:24.10.2016.

Doi Number :http://dx.doi.org/10.19129/sbad.301

\title{
ÖĞRENME OKULU'NA BİYOGRAFİK BİR YAKLAŞIM: MINTZBERG ve LINDBLOM ÜZERİNE ARAŞTIRMA
}

Mehtap ARAS*

Mintzberg tarafından geliştirilen ve stratejik yönetim yazınında kabul gören on strateji okulu 1960'lardan günümüze kadar strateji alanındaki çalışmalara çeşitli şekillerde katkı sağlamışlardır. Stratejik yönetim alanına farklı bakış açılarıyla ve ortaya attıkları kavramlarla katkı sağlayan bu okullar öngörücü okullar (prescriptiveschools ve tanımlayıcı okullar (descriptiveschools) olarak iki ana başlık altında incelenmektedir. Çalışmaya konu olan öğrenme okulu tanımlayıcı okullar arasında yer almakta olup okulun felsefesini açıklayan cümle ise; "İlkinde başarılı olamadiysan,denemekten vazgeçme" (If at firstyoudon'tsucceed, try, tryagain) dir (Mintzberg, Ahlstrand ve Lampel,1998, s.355).Öğrenme Okulu'nun ilk temsilcisi

Öz ekonomist Charles Lindblom'dur. Daha sonraları James BrianQuinn, K.E. Weick ve

Henry Mintzberg' in çalışmaları okulun gelişmesine katkı sağlamışlardır.

Çalışmanın amacı, teorisyenlerin, teori ortaya koyma ya da geliştirme çalışmalarında bilinçli/bilinçsiz kendi hayatlarından, yaşadıkları olaylardan etkilenip etkilenmediklerini ortaya koymaktır. Okulun ortaya çıkmasını sağlayan ya da katkıda bulunan yazarlardan Lindblom ve Mintzberg' in biyografilerinden hareketle yaşamları ve okula sağladıkları katkıları irdelenecek olup, bu iki yazarın hayatları ile katkıda bulundukları kavramlar arasındaki benzerlikler olup olmadığı araştırılmıştır.

Anahtar Kelimeler: Öğrenme Okulu, Lindblom, Mintzberg, Biyografi

\section{A BIOGRAPHIC APPROACH TO LEARNING SCHOOL: A STUDY on MINTZBERG and LINDBLOM}

Ten strategy schools developed by Mintzberg and accepted in strategic management literature have variously contributed to the studies in the field of strategy since 1960s. These schools which contribute to the field of strategic management with the help of different points of view and the concepts they put forward are analyzed under two categories as prescriptive schools and descriptive schools. Learning school which is handled by this study is among descriptive schools; and the sentence which explains the philosophy of the school is "If at first

Abstract you don't succeed, try, try again. (Mintzberg, Ahlstrand and Lampel, 1998, p.355). First representative of the learning school is Charles Lindblom, an economist. Then, James Brian Quinn, K.E. Weick and Henry Mintzberg have contributed to the development of this school with the help of their studies.

This study aims at asserting whether or not theorists are consciously/unconsciously affected by their own lives and experiences in their studies of suggesting or developing theories. With reference to the biographies of

\footnotetext{
* Araş.Gör.,Gaziosmanpaşa Üniversitesi, e-mail: mehtap.aras@gop.edu.tr
} 


\section{Mehtap ARAS}

Lindblom and Mintzberg who are among the writers contributing to the emergence of the school, their lives and contributions to the school will be analyzed and it has been researched whether or not there are similarities between the lives of these two writers and the concepts which they contribute to.

Key Words: Learning School,Lindblom, Mintzberg, Biography.

\section{GİRIŞ}

Strateji süreci ile ilişkili, Chaffee (1985)'ye göre üç (doğrusal, uyumlayıcı ve yorumlayı1), Whittington (2001: 11-26)'a göre dört (klasik, evrimsel, süreçsel ve sistemsel), Mintzberg (1990)'e göre on düşünce okulu vardır (Barca, 2005: 24). Bu tasniflerden biri de Kees Van Der Heijden'e aittir. Heijdenstratejinin üç farklı yolla ortaya çıktığını ve üç okul veya paradigma olduğunu ileri sürmüştür. Bunlar; rasyonalist, evrimci ve süreç okullarıdır. Rasyonalist okulu, "makine" metaforu ile açıklamaktadır. Evrimci okulu, ekoloji biliminden esinlenerek açıllayan Heijden, süreç okulunu ise yaşayan organizma betimlemesiyle ifade etmiştir (Heijden,1996, s.21-22).

Literatürde Mintzberg'in on stratejik okulu olarak geçen ve stratejik yönetim yazınına farklı bakış açılarıyla katkı sağlayan bu okullar 1960'lardan sonra gelişmiş ve ortaya çıkmışlardır. Her bir okulun stratejiye farklı katkıları olmuş ve yeni kavramlarla katkı sağlamıştır.

Mintzberg'in stratejik okulları şu şekilde sınıflandırılmıştır (Mintzberg, Ahlstrand ve Lampel, 1998: 5);

Tablo.1. Mintzberg'in Stratejik Okul Tasnifi

\begin{tabular}{|l|l|}
\hline \multicolumn{2}{|l|}{ Öngörücü Okullar (Prescriptive Schools) } \\
\hline Tasarım Okulu & Düşünce/Kavram oluşturma sürecidir. \\
\hline Planlama Okul & Formel strateji oluşturma süreçtir. \\
\hline Konumlandırma Okulu & Analitik bir strateji oluşturma süreçtir. \\
\hline Tanımlayıcı Okullar (Descriptive Schools) \\
\hline Girişimcilik Okulu & Bir vizyon yaratma sürecidir. \\
\hline Bilişsel Okul & Zihinsel bir süreçtir. \\
\hline Öğrenme Okulu & Ortaya çıkan bir süreçtir. \\
\hline Güç Okulu & Bir müzakere sürecidir. \\
\hline Kültürel Okul & Ortaklaşa bir süreçtir. \\
\hline Çevre Okulu & Tepkisel bir süreçtir. \\
\hline Bütünleştirme Okulu & Dönüşümsel bir süreçtir \\
\hline
\end{tabular}

Kaynak:Mintzberg, Ahlstrand ve Lampel, 1998: 5'den oluşturulmuştur.

İlk üç okul, öngörücü bir yaklaşımda bulunur ve stratejinin (ideal olarak) nasıl formüle edilmesi gerektiği üzerinde durur. İlk okul olan Tasarım Okulu, 1960'larda ortaya çıkmış ve temel bir çerçeve olarak sonraki iki okulun oluşmasına kaynaklık etmiştir. İkinci okul, Planlama Okulu'dur ve 1970'lerde ve öngörücü okullar arasında 


\section{Öğrenme Okulu'na Biyografik Bir Yaklaşım: Mıntzberg ve Lındblom Üzerine Araştırma}

olan son okul Konumlandırma Okulu'da 1980'lerde etkin olmuştur.Sonraki altı okul ise betimleyici bir yaklaşımla, stratejinin nasıl olması gerektiğinden çok, gerçekte nasıl olduğuyla ilgilenmiştir. Son okul, tüm diğer okulları tek bir okul çatısı altında birleştirme çabası içerisindeki bütünleştirme okuludur. Bu okul, strateji oluşturma sürecini, stratejilerin kapsamını örgütsel yapıları ve bunların münasebetleriyle ilgili farklı öğeler demetini ayrı safhalar ya da dönemler içerisinde bütünleştirmeye çalışır (Mintzberg, Ahlstrand ve Lampel, 1998: 5-6).

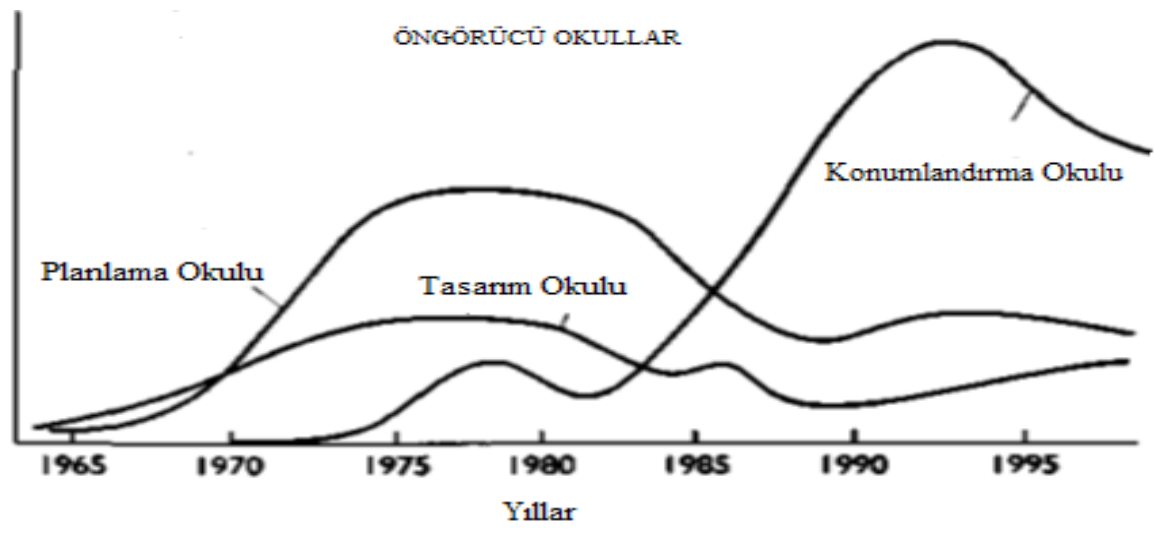

Şekil.1. Öngörücü Okulların Gelişimi Kaynak: (Mintzberg, Ahlstrand ve Lampel, 1998:353).

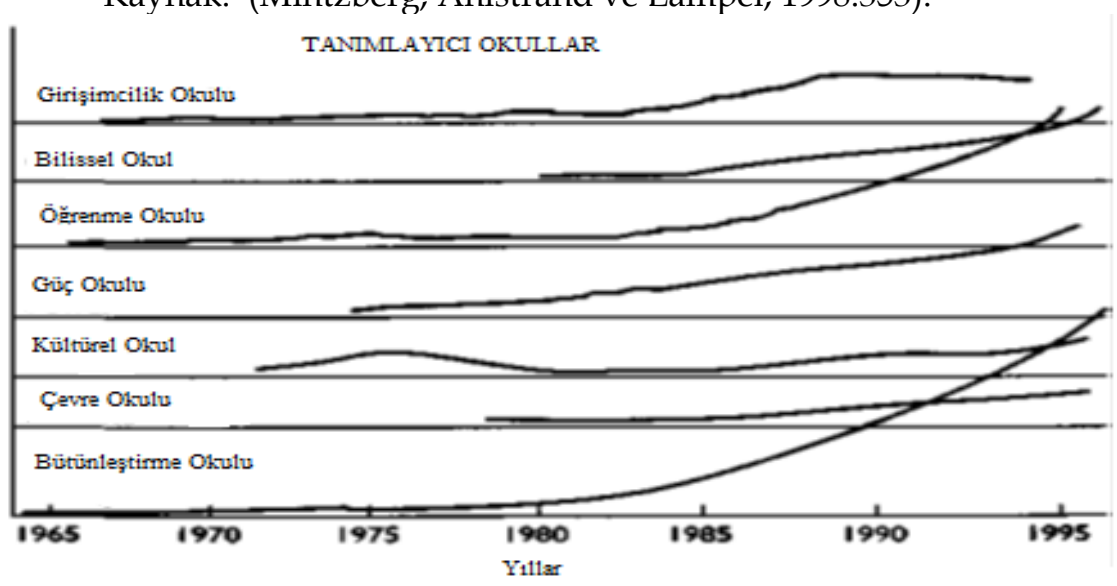

Şekil.2. Tanımlayıcı Okulların Gelişimi

Kaynak: (Mintzberg, Ahlstrand ve Lampel, 1998: 353).

$\mathrm{Bu}$ okullar, stratejik yönetimin gelişimindeki farklı safhalarda ortaya çıkmışlardır. Bunların bazıları, hâlihazırda zirveyi görmüş ve düşüşe geçmişler,

| Gaziosmanpaşa Üniversitesi Sosyal Bilimler Araştırmaları Dergisi 


\section{Mehtap ARAS}

bazılarıysa hala gelişme aşamasındadırlar. Geri kalanlarıysa kapsamlı bir literatüre sahip olmalarına karşın uygulamadaki örnekleri çok azdır (Mintzberg, Ahlstrand ve Lampel, 1998:7).

İlk ortaya çıkan okul Tasarım Okulu'dur ve stratejik yönetim yazını için çok önemli bir yere sahiptir. Öngörücü okullar olarak tasnif edilen ve Tasarım Okulu devamında ortaya çıkan Planlama ve Konumlandırma okullarının gelişmesinde de önemli bir yere sahiptir (Dinçer, 1998: 64). Okulun stratejik yönetim yazınına çevre analizi, ayrıcalıklı üstünlükler, uyum, fırsat ve tehdit gibi kavramlarla katkı sağlamasının yanı sıra stratejiyi "bilinçli bir süreç" olarak ilk kez ele almıştır. Planlama Okulu da stratejiyi "uzun dönemli resmi bir planlama süreci" olarak tanımlamıştır. (Dinçer, 1998: 64-65; Sarvanvd,, 2003: 77). Konumlandırma Okulu, kendisinden önce gelen iki okulun strateji tanımından çok uzaklaşmamaktadır. Tasarım ve Planlama okullarından farklı olarak, stratejinin ne olduğunu açıklayarak belirli bir pazarda iyi bir yer edinmek için bu duruma özel stratejiler geliştirilmesi gerektiğini savunmuştur (Dinçer, 1998: 70). Yani bir işletmenin yüksek performans sergilemesi için öncelikle doğru bir pazar seçilmesi gerekmektedir.

Tanımlayıcı okulların ilki olan Girişimcilik Okulu, strateji oluşma sürecini tek bir lider üzerinden açılamakla kalmayıp sezgi, muhakeme, bilgelik, tecrübe ve kavrama gibi doğuştan gelen yeteneklere ve bu özelliklerle ilintili olarak "vizyon" olarak tanımlanan imaj ve yön duygusuna da vurgu yapmaktadır. Okulun tanımlayan en temel kavram; stratejinin, liderin zihninde oluşan ya da en azından canlanan bir yansıması olan "vizyon" kavramidır(Mintzberg, Ahlstrand ve Lampel, 1998: 124). Bilişsel Okul, psikoloji biliminin "biliş" kavramına dayanmaktadır. Okulun verdiği mesaj ise "merak et" ve "hayalini kur"dur (Mintzberg, Ahlstrand ve Lampel, 1998: 354). Bu okul, strateji oluşturmayı zihinsel bir süreç olarak ve planlanan değil ortaya çıkan bir strateji olarak tanımlar (Bakoğlu ve Özcan, 2010: 63). Okulun temel mantığına göre, strateji oluşturmanın temeli biliştir ve insan bilişinde stratejinin nasıl oluştuğunu araştırır (Sarvan vd.,2003: 86). Güç okulu, temelini siyaset biliminden alır ve verdiği mesaj "paylaşmak yerine sakla" dır. Kültür okulu' nun dayandığı disiplin antropolojidir ve verdiği mesaj "değişim yerine ebedîleşmektir". Çevre Okulu'nun dayandığ disiplinler ise biyoloji ve siyasal sosyolojidir. Verdiği mesaj ise "karşı koymak yerine anlaşmak/teslim olmaktır" (Mintzberg, Ahlstrand ve Lampel, 1998: 355).

\section{1. Öğrenme Okulunun Temel Varsayımları}

Öğrenme okulunun temeli1959 yılında Charles Lindblom tarafından yazılan "TheScience of Mudding Through" makalesine dayanmaktadır. Lindblom bu yazısında özetle, dünyanın doğasının kompleks yapısından dolayı devletin düzenli, sistemli ve kontrollü bir politika yapmaya ihtiyacı olmadığını öne sürmüştür. Lindblom'un çalışmasının ardından öğrenme okuluna katkı yapan düşünürler 


\section{Öğrenme Okulu'na Biyografik Bir Yaklaşım: Mıntzberg ve Lındblom Üzerine Araştırma}

H.EdwardWrapp'ın 1967'de yazdığı “GoodManagersDon'tMakePolicyDecisions" çalışmasından da etkilenmişlerdir (Lindblom, 1959, Quaye vd., 2015).

Öğrenme okuluna göre dünya, tek seferlik net planlar ve stratejiler geliştirmeye olanak vermeyecek kadar karmaşık ve çok katmanlıdır. Bundan dolayı, stratejiler, örgütsel adaptasyon veya öğrenme biçimindeki küçük adımlar şeklinde ortaya çıkmalıdır (Mintzberg, Ahlstrand ve Lampel, 1998: 6).

Öğrenme Okulu psikoloji ve eğitim bilimlerinde öğrenme kuramı ile birlikte matematiktekaos kuramına dayanmaktadır. Öğrenme okulunun vermek istediği mesaj "öğren", gerçekleşen mesaj ise "oynamak izlemekten iyidir" (Mintzberg, Ahlstrand ve Lampel, 1998: 355) . Öğrenme Okulu'nun temel felsefesi yukarıda değinildiği gibi sürekli öğrenme üzerine kurulmuştur.

Öğrenme Okulu Lindblom'unilk çalışmalarından olan kopuk adımlarla ilerleme üzerine yaptığ 1 çalışmalara dayanmakla birlikte, Quinn'in mantıklı adımlarla ilerleme, Bower'ın stratejik girişimler, Mintzbergvd'.nin ortaya çıkan strateji (emergentstrategy)ve Weick'in geçmişe bakış okulun gelişmesine önemli katkılar sağlamıştır (Mintzberg ve Lampel, 1999: 25).

Mintzberg (1978a: 935)'e göre strateji bir plan değil, "karar sürecinde ortaya çıkan bir model" dir. Bu nedenle, stratejiyi açık olarak ifade etmeye ihtiyaç olmadığı gibi bilinçli olarak geliştirmek de gerekmemektedir. Öğrenme okuluna göre strateji, uygulamadan önceortaya çıkan bilinçli olarak karar verilen ve planlanan bir durum olmaktan ziyade, uygulama içerisindeki öğrenme sürecinde deneme yanılma yoluyla ortaya çıkan çeşitli kararların ortaya çıkardı̆̆ı ve geriye dönüp bakıldı̆̆ında fark edilebilecek bir süreçtir (Barca, 2005: 25). Özetle, strateji plan değil, içerisinde öğrenme süreci olan kararlar dizisidir (Özdemirci, 2010: 71).

Öğrenme okulu temeli öngörmekten çok tanımlamaktır. Bu okulun sürekli sorduğu basit ama en önemli soru: "Stratejiler aslında organizasyonda nasıl oluşurlar?",yani nasıl formüle edildiği değil nasıl oluştuğudur (Mintzberg, Ahlstrand ve Lampel, 1998:177).

Öğrenme Okulu'nun en önemli varsayımlarından biri geleceğin belirsizliğinden dolayı geleceği tam olarak tahmin etmenin mümkün olamayacağıdır. Bir diğer varsayım,yaşanan her duruma veya soruna ait alternatif çözümlerin veya davranışların tam anlamıla bilinmeyeceği ve değerlendirilemeyeceğidir. Geleceğin belirsiz, yaşanan sorunların çözüm alternatiflerinin tamamının bilinememesi ve değerlendirilememesi düşünüldüğünde alındığında geleceğe dair rasyonel stratejik plan yapmakta zorlaşmaktadır. Stratejiler, zaman içinde örgütlerin yaptıkları eylem ve aldıkları kararlarla kendiliğinden ortaya çıkan durumlardır. Yani strateji örgütlerin zaman içerisinde biçimlenen bir öğrenme süreci şeklindedir (Sarvanvd., 2003: 94).

Öğrenme okuluyla birlikte anılan terimler ise şu şekildedir; oluşan strateji (emergentstrategy), öngörme (prescriptive), artan (incremental) ve karmaşı öğrenme süreci (complexlearningprocess) (Kipley, 2009:3).

| Gaziosmanpaşa Üniversitesi Sosyal Bilimler Araştırmaları Dergisi 


\section{Mehtap ARAS}

Öğrenme Okulu'nun ilk temsilcisi ekonomist Charles Lindblom'dur. Daha sonraları James BrianQuinn, K.E. Weick ve Henry Mintzberg'in çalışmaları okulun gelişmesine katkı sağlamışlardır.

\section{Lindblom ve Öğrenme Okulu'na Katkı Sağladığı “Kopuk Adımlarla İlerleme} veya Parçalı Büyümecilik" (DisjointedIncrementalizm) Yaklaşımı

Charles Lindblom'un çalışmaları hem kamu yönetimi alanı ile ilgilihem de işletmelerin politika belirleme süreçlerini açıklamaya yöneliktir (Sarvanvd.,2003: 91).

Lindblom konuyla ilgili "Thescience of muddlingthrough" adlı eserinde, yöneticilerin politika geliştirmek için kök (root) ve dal (branch) metodu olarak iki karar süreci olduğunu belirtmektedir (Lindblom, 1959: 80-81). Kök metodu, amaca ulaşmak için mümkün olan alternatiflerin tamamını sistemli bir şekilde değerlendiren, mantığa dayalı rasyonel bir yaklaşımdır. Yeni bir politika için oluştururken karar verici, geçmiş tecrübelerinden yararlanır. Fakat bu metot karmaşık politika sorunları için etkili bir yöntem değildir. Dal karar verme metodu ise "ardışık sınırlı mukayese" olarak tanımlanabilir. Dal metodu düşük seviyeli problemleri çözmede kullanılır.Bu metotta, politikalar mevcut faaliyet ve şartlardan kaynaklanır, azar azar ve adım adım inşa edilir (Lindblom, 1959: 80-81; Dinçer, 1998: 83).

"Thescience of muddlingthrough" adlı meşhur eserinde Lindblom karar vermenin rasyonel modellerini eleştirmiş ve gerçekte rasyonel modellerin işlemediğini deöne sürerek, karar alıcıların küçük ve adım adım kararlar vermeleri gerektiğini savunmuştur (Pindur, Rogers ve Kim, 1995: 66-67).

Lindblom, bu düşünce okuluna katkıyı, "Kopuk Adımlarla İlerleme” kavramı ile yapmiştır.Lindblom(1968: 25-26, akt. Mintzberg, Ahlstrand ve Lampel, 1998)'un ifadesiyle politika oluşturma, "iyi bir ısırmanın yerini sürekli ve ardışık ısırıkların aldığı sonsuz bir süreçtir". Başka bir ifadeyle, yazarın temel iddiası, politika geliştirmenin sade, düzenli ve kontrollü süreç olmadığı; karar vericinin karmaşık durumların üstesinden gelebilmek için seri şekilde çare bulan ve parça parça davranışlarından ortaya çıktığıdır (Mintzberg, Ahlstrand ve Lampel, 1998: 179-180).

Lindblom'a (1979:517) göre, politika oluşturmada ufak adımlarla ilerleme (incrementalism yada muddlingthrough) olağan yöntem olarak kullanılmalıdır. Ne devrim, ne köklü politika değişiklikleri, ne de dikkatle planlanmış büyük adımlar politika oluşturmak için mümkün değildir. 


\section{Öğrenme Okulu'na Biyografik Bir Yaklaşım: Mıntzberg ve Lındblom Üzerine Araştırma}

\subsection{Lindblom'un Hayatı1 ve "Kopuk Adımlarla İlerleme" Kavramının Öğrenme Okuluna Yansiması}

Charles Edward Lindblom, 1917 yılında Amerika'da doğmuştur. Üniversite hayatına Standford Üniversitesinde başlayıp, Chicago Üniversitesinden mezun olmuştur. 1936'da Minnesota Üniversitesinde Ekonomi dersleri vermeye başlamış ve öğrenci kulüplerinde yaptığı konuşmalardan dolayı bölüm başkanı tarafından azarlanmıştır. Bunun üzerine Lindblom görevini tamamlamadan Yale Üniversitesine geçmiştir. Ekonomi disiplininin katılığından hoşlanmamasına rağmen bu alana çok farklı düşüncelerle katkı sağlamıştır.

Lindblom'un araştırma soruları ve metodolojisi alanla ilgisiz olduğu için Yale ekonomi bölümü tarafından istifa etmesi istenmiştir. Yale'deki akademisyenler onun asla Profesör olamayacağını düşünüyorlardı. Robert Dahl ile birlikte siyaset bilimi üzerine çalışmaya başlamaları onun akademik hayatının dönüm noktası olmuştur. 1972- 1974 yılları arasında siyaset bilimi bölümünün başkanlığını yapmış ve daha sonraları Yale'de Ekonomi ve Siyaset Bilim Dalının en prestijli başkanı olarak seçilmiştir. Amerikan Siyasal Bilimler Derneği'nin ve Karşılaştırmalı Ekonomik Araştırmalar Derneğinin başkanlığını da yapmıştır.

Yale Üniversitesin Siyaset Bilimi ve Ekonomi kürsüsünde çalışmış ve emekli olmuştur. Karar almada ve politikada adımı adım ilerleme teorisinin ilk savunucularındandır. Karar almada "bebek adımları" ve "parçalı büyüme" yaklaşımı olarak ta adlandırılır. Hâlâ "TheScience of Muddling Through" adlı çalışması binlerce atıf almaktadır.

Linblom'un kariyeri sürekli artan bir grafik göstermemektedir. Hatta çalışmalarından dolayı işinden olmakla yüz yüze gelmiştir. Etrafındaki insanlarda aslında onun bu ilerleyişine ve çalışmalarına bakarak onun Profesör unvanını bile alamayacağını düşünmüşlerdir. Öğrenme okuluna katkısı "parçalı büyüme" olan Lindblom aslında kendi kariyerinde de aynen böyle yapmıştır. Kendi isteği ile olmasa da Lindblom bazı durumlarda buna mecbur bırakılmıştır. Kariyerinde "büyük ısırıklar" alıp bir anda yükselmeyi hedeflemeyen Lindblom, "küçük adımlarla" alanında çok tanınan ve farklı fikirleriyle, farklı bakış açılarıyla literatüre katkı sağlayan bir Profesör olmuştur. Planlanmış büyük adımlar yerine küçük ve emin adımlar atılması gerektiğini söyleyen Lindblom kuşkusuz kendi kariyerinde de bu şekilde ilerlemiştir.

\section{Henry Mintzberg ve "Ortaya Çıkan Strateji (EmergentStrategy)"}

Mintzberg stratejiyi işletmenin faaliyetleri esnasında ortaya çıkan ve her zaman örgütün rasyonel planlamaların sonucu olmayan bir durum olarak ifade etmiştir.

${ }^{1}$ Charles Edward Lindblom hayatı International Encyclopedia of TheSocialSciences, 2nd Edition'dan oluşturulmuştur.

| Gaziosmanpaşa Üniversitesi Sosyal Bilimler Araştırmaları Dergisi 


\section{Mehtap ARAS}

Stratejinin belirli bir plan yapmadan ve örgütün geçmişte yaşadığ 1 şeylerden çıkarabileceğini savunmuştur. Strateji, planlanan şeylerden ziyade işletmenin yaptıklarıyla ilgili bir dizi karar ve faaliyetlerinin sonucunda ortaya çıkan bir durumdur(Dinçer, 1998:86-87).

Stratejilerin bir plan olarak tanımlanması fikrine karşı çıkan Mintzberg, stratejiyi faaliyet esnasında ortaya çıkan bir model olarak tanımlamaktadır. Mintzberg'e göre strateji her zaman rasyonel planların sonucunda oluşmaz, bir plan olmadan da strateji gelişebilir. Bu düşünceden hareketle, niyet edilen (intented) ve tam olarak gerçekleşen (realized) stratejilere "kasitlı stratejiler" (deliberatestrategy) adı verilebilir. Niyet edildiği halde gerçekleşemeyen stratejilere de "gerçekleşmeyen stratejiler" (unrealized) adı verilmektedir. Bu iki stratejinin dişında bir üçüncü strateji olarak niyet edilmediği halde gerçekleşen stratejiler vardır. Niyet edilmediği halde gerçekleşen stratejilere ise ortaya çıan strateji(emergentstrategy) adı verilir. Şayet stratejilerin tamamı kasıtlı ya da tamamı ortaya çıkan stratejiler ise, öğrenmeyi ya da kontrolü barındırmıyorlar demektir. Gerçek dünyada ise bu ikisinin harmanlanması gerekmektedir. Diğer bir ifadeyle stratejiler, formüle edildiği kadar şekillendirilmelidir (Mintzberg, Ahlstrand ve Lampel, 1998: 11).

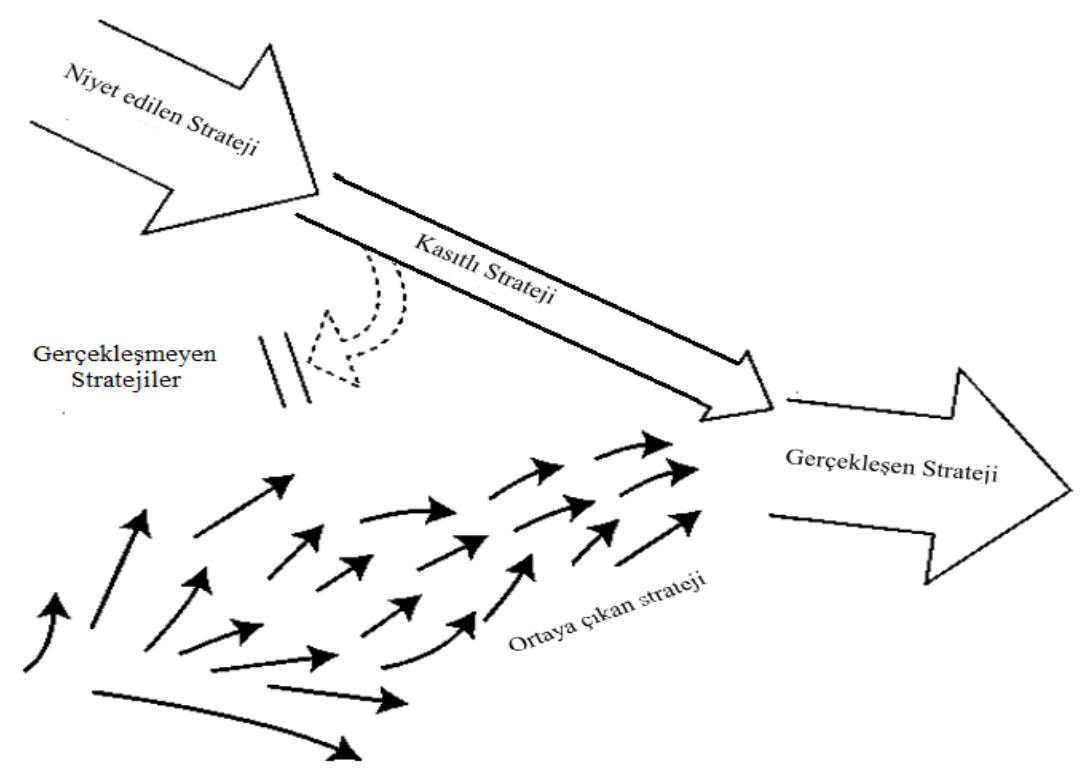

Şekil.3. Kasıtlı ve Ortaya Çıkan Strateji Modeli Kaynak: Mintzberg, H. , B.Ahlstrand ve J. Lampel (1998), Strategy Safari: A GuidedTour Through TheWilds of Strategic Management. TheFreePress, NewYork. s.12. 


\section{Öğrenme Okulu'na Biyografik Bir Yaklaşım: Mıntzberg ve Lındblom Üzerine Araştırma}

Kasıtlı stratejileri iyi, ortaya çıkan stratejileri kötü olarak nitelendirmek doğru değildir. Her ikisinin de bir arada olması gerekmektedir.

Sonuç olarak, Mintzberg strateji geliştirmeyi uygulamanın içinden gelen ve uygulama ile birlikte düşünülen bir durum olarak görmekte ve bu durumun beş özelliğini şu maddelerle ifade etmektedir (Dinçer, 1998: 88);

1. Strateji hem gelecek için plan, hem de geçmişten gelen bir numunedir.

2. Stratejiler sadece planlanarak ortaya çıkmaz, aynı zamanda mevcut durumlardan kaynaklanir.

3. Etkili stratejiler çok çeşitli yollardan geliştirilebilir.

4. Stratejik yönlendirmeler küçük sıçramalarla ortaya çıkar.

5. Bütün bunlardan sonra strateji, düşünce ile eylemi, kontrol ile öğrenmeyi, durgunluk ve değişimi birlikte ele almanın bir zanaatı olarak gelişir.

\subsection{Henry Mintzberg'in Hayatı ve Öğrenme Okuluna Yansımaları²}

Mintzberg 2 Eylül 1939 ta Montreal'de doğmuştur. SashaSadilova ile evli olan Mintzberg'in Susie ve Lisa adlarında önceki evliliğinden iki kız çocuğu vardır. Hobileri uzun bisiklet turları yapmak, kanoya binmek, kayak ve yürüyüş yapmak, dağa çıkmak, kısa hikâyeler yazmak ve kunduz heykelleri biriktirmektir.

McGill Üniversitesi Makine Mühendisliği bölümünden mezun olan Mintzberg, MIT (Massachusetts Institute of Technology) Sloan School of Management'da yüksek lisansını (1965) ve doktorasını (1968) tamamlamıştır. 1968 yılından beri Kanada, Montreal' de McGill Üniversitesinde Öğretim üyeliği yapmaktadır.

İşletme ve yönetim stratejileri üzerine 170'eyakın makale ve 17 kitap yazmıştır. Yaptığı bu çalışmalarla birlikte Mintzberg 30'a yakın ödül almıştır. Yeni ufuklar açan "Stratejik Planlamanın Yükselişi ve Düşüşü" (1994) adlı kitabı günümüz stratejik planlarının eleştirisi niteliğindedir. "Managers not MBAs" (2004) kitabında ise yönetim eğitiminin yanlış olduğunu ileri sürmüştür.Harvard Business School ve Wharton Business School gibi lisansüstü eğitim veren okulların yönetim disiplinine zarar verdiğini belirtmiştir. Gerçek iş tecrübeleriyle değilde okulda eğitim alarak yönetici olunamayacağını savunmuştur. 2 kez Harvard Business Review'de yayımlanan stratejik danışmanlıkla ilgili makalelerinden dolayı McKinsey Ödülü almıştır.

Mintzberg, 1978 yllında Ten yearslater: somepersonalreflections on managementandmethology adlı bir yazı kaleme almıştır. 1993 yılında ise "TheIllusiveStrategy 25 yearslater" adlı nasıl örgüt ve yönetimle ilgili çalışmalar yaptığını, kariyerini anlatan yazısında şöyle demiştir:

"Bir gün bir arkadaşımla yürüyüş yaparken bana "Örgütlerle ilgili çalışmalar yapmaya nasıl karar verdin?" diye sordu. Bende "bilmem,

\footnotetext{
${ }^{2}$ Henry Mintzberg'in hayatında, TheIllusiveStrategy....25 YearsLater, Arthur Bedeian Management Laureates: A Collection of AutobiographicalEssays,(JAI Press, Volume II'den yararlanılmıştır.
}

| Gaziosmanpaşa Üniversitesi Sosyal Bilimler Araştırmaları Dergisi 


\section{Mehtap ARAS}

sadece oldu" dedim. Bunu gerçekten de hiç düşünmemiştim. Ama çok iyi oldu. Aslinda bu soruyu cevaplamak için biraz geçmişime bakmak gerekiyor galiba. Küçük sevimli konforlu bir ailede dünyaya geldim. Babam kadın elbiseleri yapan küçük bir işletmeye sahipti ve onun "bir yönetici" olarak ofisinde ne yaptığın hep merak ederdim. Stradan bir çocuk olarak büyüdüm ve kötü bir öğrenci de değildim. Lisede makina mühendisliği okumaya karar verdim. Parçaları bir araya getirmeye bayılırdım (hepsini asla bir araya getirememe rağmen). Aslında endüstri mühendisi olmak istiyordum ama McGill'in bu programı yoktu. Yazlarım genellikle fabrikalarda çalışmakla geçti. Mezun olunca ne yapacağım konusunda kesin bir karar vermemiştim ama babamla da çalışmak istemiyordum. Kendi başıma bir şeyleri başarabileceğimi görmem gerekiyordu. McGill gazetesinde spor yazarı olarak çalışmaya başladım.

Her zaman küçük şirketlere danı̧̧manlı yapmak için endüstri mühendisliği ya da operasyonel araştırmalar alaninda yüksek lisans yapmak istedim. Aslında çok yakın olmadiğım amcam JackMintzberg beni bu konuda destekledi. Aslında sonradan fark ettim ki akademik kariyer yapma fikrini aklıma ilk o yerleştirdi. Amcam bir ara araştırma görevlisi olarak çalışt ve zihnimin derinliklerinde akademisyen olma fikri bundan kaynaklanıyor olabilir.

New York Üniversitesinde endüstri mühendisliği yüksek lisans programına başvurdum. Kabul edildikten sonra Columbia Üniversitesi işletme bölümüne de başvurdum. Her ikisine de kabul edildikten sonra karar vermek için SebastianB.Littauer'in yanına gidip fikrini almak istedim. Bana "Onları seç, onların senin için yapacakların biz yapamayız" dedi. Bir insanın hayatındaki "en kritik" anlardan biriydi. MIT (Massachusetts Institute of Technology) Sloan School of Management'ta yüksek lisansimı tamamladim ve doktora programina kaydoldum. Doktora programına neden kaydolduğumu bilmiyorum belkide kısa yoldan bir iş sahibi olmayı istiyordum yada işletmelerdeki sorunlara ilgim giderek artmışt, belkide her ikisi.

Doktorada politika alanında çalışmak istedim fakat bunula ilgili hiçbir ders verilmiyordu. Politika alanında Profesör yoktu. Başvurum komitede değerlendirildi ve komitede politika çalışan Edward Bowman vard. Bowman bu başvurumu kabul ettirdi ve kendisinin bana danışmanlik yapacağın söyledi. Bowman bir gün bana "Politikada gelecek yok, fikrini değiştirmen gerekiyor" dedi. Fakat ben vazgeçmedim."

| Gaziosmanpasa University Social Sciences Researches Journal 


\section{Öğrenme Okulu'na Biyografik Bir Yaklaşım: Mıntzberg ve Lındblom Üzerine Araştırma}

Mintzberg stratejiyi faaliyet esnasında ortaya çıkan bir durum olarak tanımlamıştır ve Mintzberg'e göre niyet edilen strateji her zaman gerçekleşmeyebilir. Minzberg'in hayatının bazı kısımlarında da bu böyle olmuştur. Endüstri mühendisliği okumak isterken gitmek istediği okulda bu bölüm olmadığı için makina mühendisliği okumak zorunda kalmış ve yine yüksek lisans için Endüstri mühendisliğibölümüne başvurmuş ve aslında istediği bölüm de o olmasına rağmen yapmak istediği şeyler işletme bölümünde olduğu için bu alana kaymak zorunda kalmıştır. Aslında kariyerini strateji üzerine yapmayı ve işletme sorunlarını irdelemeyi hiç aklından geçirmeyen Mintzberg, hayatının akışı doğrultusunda geriye baktığında hiç de planlamadığı bir konuma gelmiştir.

Mintzberg'e göre strateji, faaliyet esnasında ortaya çıkan ve rasyonel planların sonucu olmayan bir durumdur. Mintzberg'in kariyerine bakıldığında, strateji ile ilgili görüşlerinde ve stratejiye bakış açısında yaşamından etkilendiği söylenebilir. Mintzberg'e göre niyet edilen strateji her zaman gerçekleşmeyebilir. Rasyonel bir strateji belirleyerek yola çıkarken göz önünde bulundurulmayan durumlar meydana gelebilir ve niyet edilen stratejilerin bir kısmı gerçekleşmeyebilir. Ortaya çıkan durumlara göre strateji şekil değiştirebilir ve ulaşılan sonuç bu yönde farklılaşabilir. Bununla birlikteMintzberg, stratejinin hem plan hem de geçmişten gelen bir durum olduğunu söylerken, hayatına baktığımızda akademik kariyeri yapmasına etkili olan şey aslında amcasının araştırma görevlisi olarak çalışması ve teşvik etmesi, babasının küçük işletmesinde yönetim işlerinin nasıl yapıldığını merak etmesi yatmaktadır. Niyeti Endüstri mühendisliği okumak olan Mintzberg, McGill'de bu bölümün olmaması nedeni ile makine mühendisliği okumak durumunda kalmıştır ve Makina Mühendisliği okuyan bir kişinin işletme gurusu haline gelmesi aslındaMintzberg'in strateji tanımı ile paralellik göstermektedir. Kendisinin de ifade ettiği gibi "Sadece oldu".

\section{SONUÇ}

Stratejik yönetim yazınına farklı düşünce şekilleriyle ve bakış açılarıyla katkı sağlayan stratejik düşünce okullarının her biri şüphesiz bu alanın gelişmesine fayda sağlamışlardır. Farklı disiplinlerde farklı kuramlara dayandırılan ve en çok kabul gören sinıflandırma ise Mintzberg'e aittir. Mintzberg' in yanı sıra birçok teorisyen okulların gelişmesine katkı sağlamışlar ve on strateji okulu olarak bilinen bu sınıflandırmada kavram bakımından en zengin olan okulların başında ise Öğrenme Okulu yer almaktadır.Öğrenme Okulu, psikoloji ve eğitim bilimlerinde öğrenme kuramı, matematikte ise kaos kuramına dayandırılmıştır. Okulun temeli "öğrenmeye" dayanmaktadır. Geçmişte yaşananlardan ve hali hazırda yaşanan durumlardan faydalanarak geleceği planlamak ya da mevcut durumda yaşanılanlardan ders alarak strateji oluşturmaktır.

Çalışmada Öğrenme okuluna katkı sağlayan ve gelişmesine yardımcı olan Henry

| Gaziosmanpaşa Üniversitesi Sosyal Bilimler Araştırmaları Dergisi 


\section{Mehtap ARAS}

Mintzberg ve Charles Edward Lindblom'un kendi hayatlarında yaşadıkları olayların okula sağladıkları katkıların benzer olup olmadığını irdelenmiştir. Lindblom'un okula kazandırdığı kavram "Kopuk Adımlarla İlerleme veya Parçalı Büyümecilik" (DisjointedIncrementalizm)tir. Kariyerinde yaşadığ1 zorluklar ve hatta bir dönem istifaya zorlanması onun akademisyenlik hayatında dönüm noktası olmuş ve parçalı olarak kariyerini devam ettirmiştir. Bu kavramı ortaya atan Lindblom bilinçli/bilinçsiz kendi hayatından etkilenmiş olabilir.

Mintzberg stratejinin planlı bir eylem olduğu fikrine karşı çıkmıştır ve stratejiyi faaliyet esnasında ortaya çıkan bir model olarak tanımlamaktadır.Mintzberg'e göre strateji her zaman rasyonel planların sonucunda oluşmaz, bir plan olmadan da strateji gelişebilir. Kariyerinde rasyonel bir plan olarak nitelendirebileceğimiz endüstri mühendisliği okumak isteğiyle yola çıkan Mintzberg, istediği okulda bu bölüm olmadığından dolayı makine mühendisliği okumuştur. Mintzberg, niyet edilen (intented) strateji veniyet edildiği halde gerçekleşemeyen stratejilere "gerçekleşmeyen stratejiler" (unrealized) kavramlarını geliştirmiştir. Endüstri mühendisliği okumak onun için niyet edilen bir stratejidir fakat şartlar uygun olmadığından dolayı bu stratejisi gerçekleşmemiştir. Daha sonra endüstri mühendisliği ve işletme yüksek lisansı yapmak arasında kararsız kalan Mintzberg, tercihini işletmeden yana kullanmıştır. Bu durum da niyet edilmediği halde gerçekleşen strateji yani ortaya çıkan strateji (emergentstrategy) kavramına örnekolarak verilebilir.Öğrenme okulunun stratejik yönetime katkılarından biri de stratejinin sadece planlanarak yapılamayacağ öngörülemeyen durumlarda "emergentstrategy" yani oluşan stratejilerle ilerlemek zorunda kalınabileceğidir.Mühendislik kariyeri planı ile yola çıkan Mintzberg bir işletme gurusu haline gelmiştir. Arkadaşının; "Örgütlerle ilgili çalışmalar yapmaya nasıl karar verdin?" sorusuna "bilmem, sadece oldu" cevabını veren Mintzberg, okula kazandırdığı "ortaya çıkan strateji" (emergentstrategy) kavramına da örnek olarak gösterilebilir.

Teorisyenlerin oluşturdukları teorilerde ya da katkılarında kendi yaşamlarından biliçli/bilinçsiz etkilenip etkilenmedikleri fikrinden yola çıkarak yapılan bu çalışmada biyografileri incelenen iki yazarın da kavram ve yaşamları arasında benzerlikler bulunmaktadır. Özellikle Mintzberg'in yaşamı ve kariyeri ile öğrenme okuluna kazandırdığı kavramlar arasında önemli ölçüde benzerlik vardır. Temeli öğrenme olan okulun yazarları da kendi yaşamlarından öğrendikleri ile kurama katkı sağladıkları söylenebilir. 


\section{Öğrenme Okulu'na Biyografik Bir Yaklaşım: Mıntzberg ve Lındblom Üzerine Araştırma}

\section{KAYNAKÇA}

Chaffe, E.E. (1985),“Three Models of Strategy”, Academy of Management Review. 10.1, 89-98.

Bakoğlu, R. ve Özcan, E. (2010), “İşletme Düzeyinde Strateji Paradokslarının Mintzberg'in On Stratejik Yönetim Okulu Açısından Değerlendirilmesi", Öneri Dergisi, 9.34, 57-69.

Barca, M.(2005), “Stratejik Yönetim Düşüncesinin Evrimi: Bilimsel Bir Disiplinin Oluşma Hikâyesi", Yönetim Araştırmaları Dergisi, Cilt:5, Sayı:1.

Darity, W.A. (2008), International Encyclopedia of TheSocialSciences, 2nd Edition, s. $452-454$.

http://homepages.rpi.edu/ woodhe/docs/Lindblom \%20in\%20Int1\%20Ency \%20Soc\% 20Sci.pdf

Dinçer, Ö. (1998), Stratejik Yönetim ve İşletme Politikası,Beta Basım, İstanbul.(5.Baskı)

Heijden, K.(1996), "Scenarios: The Art of Strategic Conversation", John WileyandSons, Chichester. s.23-52.

Kipley,D. (2009), “A TricotomicExamination of the Planning School Learning School, andPositioning School RelativetoAchieving Optimal Financial Performance in DiscontinuousEnvironmentalTurbulenceLevels", Journal of Management Research, 1.2, 1-16.

Quaye, I.,A. Oesi, A. Sarbah ve E. Abrokwah (2015), "TheApplicability of the Learning School Model of StrategyFormulation (StrategyFormulation as an EmergentProcess)". Open Journal of Buisnessand Management, 3, 135-154.

Lindblom, C.E. (1959), "TheScience of 'Muddling Through'”, Public Administration Review, 19: 79-88.

Lindblom, C. E.(1968), "ThePolicy-MakingProcess" , EnglewoodCliffs, NJ: PrenticeHall.

Lindblom, C. E. (1979), "StillMuddling, Not Yet Through", Public Administration Review, November/December, s. 517-526.

Mintzberg, H.(1993), ThelllusiveStrategy....25 YearsLater, Arthur Bedeian Management Laureates: A Collection of AutobiographicalEssays,(JAI Press, Volume II).

Erişim: http:// www.mintzberg.org/sites/default/files/page/25years.pdf

Mintzberg, H. (1978a), "Patterns in StrategyFormation", Management Science, 24.9, 934-948.

Mintzberg, H.(1978b), Ten YearsLater: SomePersonalReflections on Management andMethodology (WorkingPaper, 1978)

Mintzberg, H. (1990),StrategyFormation: Schools of Thought. J.W. Fredericson (Ed.), Perspectives on Strategic Management: 105-235. London: HarperBusiness.

Mintzberg, H. ve J. Lampel(1999), "Reflecting on theStrategyProcess",Sloan Management Review. 40.3, 21-30.

| Gaziosmanpaşa Üniversitesi Sosyal Bilimler Araştırmaları Dergisi 


\section{Mehtap ARAS}

Mintzberg, H. , B.Ahlstrand ve J. Lampel(1998), Strategy Safari: A GuidedTour Through TheWilds of Strategic Management. TheFreePress ,New York.

Özdemirci, A.(2010), “Strateji Sürecinin Planlılık Düzeyi, Liderlik Stilleri ve Çevresel Koşulların Örgütsel Uyumlanma Üzerindeki Etkisi: İso'ya Bağlı İşletmeler Üzerinde Bir Araştırma", Yayımlanmamış Doktora Tezi, Marmara Üniversitesi Sosyal Bilimler Enstitüsü, İstanbul.

Pindur, W., S.E. Rogers ve P.S. Kim (1995), “TheHistory of Management: A Global Perspective", Journal of Management History, 1.1, 59-77.

Sarvan, F., Arıcı, E., Özen, J., Özdemir, B., İçigen, T.(2003). “On Stratejik Yönetim Okulu: Biçimleşme Okulunun Bütünleştirici Çerçevesi". Akdeniz İ̇BF Dergisi, 6. 73-122.

Wrapp, H.E. (1967), “GoodManagersDon'tMakePolicyDecisions”, Harvard Business Review, 45.5, 91-99.

Whittington, R.(2001), What is strategyanddoes it matter? London: FerdinnandPageworks.

https:/ / books.google.com.tr/books?id=PP6IMSkbYWoC\&printsec $=$ frontcover\&dq=W hat+is+strategy+and+does+it+matter $\% 3 F \& h l=t r \& s a=X \& r e d i r \_e s c=y \# v=$ onepa ge\&q=What $\% 20$ is $\% 20$ strategy $\% 20$ and $\% 20$ does $\% 20$ it $\% 20$ matter $\% 3 \mathrm{~F} \& \mathrm{f}=$ false 